\title{
Lung Soft Tissue Tumors
}

The following is the list of primary soft tissue tumors of the lungs according to the World Health Organization classification published in 2015.

Since lungs are the most frequent site of soft tissue sarcoma metastases, sarcomas arising in the lungs are collectively known as primary pulmonary sarcomas.

For details on each single neoplasm $\rightarrow$ see dedicated sections.

\begin{tabular}{l|l}
\hline Tumor & Notes \\
\hline $\begin{array}{l}\text { Diffuse pulmonary } \\
\text { lymphangiomatosis }\end{array}$ & - \\
\hline $\begin{array}{l}\text { Epithelioid } \\
\text { hemangioendothelioma }\end{array}$ & - \\
\hline Intimal sarcoma & Referred to an intimal sarcoma arising in the pulmonary artery \\
\hline $\begin{array}{l}\text { Inflammatory } \\
\text { myofibroblastic tumor }\end{array}$ & - \\
\hline Lung chondroma & - \\
\hline Myoepithelioma & - \\
\hline PEComa & $\begin{array}{l}\text { Including lymphangioleiomyomatosis, PEComa benign, } \\
\text { PEComa malignant and clear cell sugar tumor of the lung }\end{array}$ \\
\hline Pleuropulmonary blastoma & - \\
\hline Pulmonary hamartoma & See section entitled "Lung Chondroma" \\
\hline Pulmonary myxoid sarcoma & - \\
\hline Synovial sarcoma & - \\
\hline
\end{tabular}

Other soft tissue tumors such as (extrapleural) solitary fibrous tumor and SMARC-deficient thoracic sarcoma can arise in the lungs and are described in this book $(\rightarrow$ see dedicated sections). 